\title{
DIRECTIONS OF CHANGES IN ORGANIZATIONAL STRUCTURES OF SME - RESULTS OF EMPIRICAL RESEARCH
}

\author{
Wioletta MIERZEJEWSKA \\ Warsaw School of Economics, Institute of Management, Warsaw, Poland \\ e-mail: wjakub@sgh.waw.pl
}

\begin{abstract}
The article presents results of empirical research concerning the directions of changes in organizational structures of SME which have occurred during the last few years. The research was carried out in a group of 380 enterprises running their businesses in Poland. The organizational structure generally described in respect of parameters such as centralization, formalization, standardization and configuration. The main part of this article is dedicated to changes that have occurred in organizational structures of SME.
\end{abstract}

Keywords: organizational structure, change, centralization, formalization, standardization, configuration.

\section{$1 \quad$ Introduction}

Organizational structure is a system of certain elements and their relations which should make it possible to attain goals of an enterprise. Forming organizational structure and the organizational structure itself is very important for correct functioning of the entire enterprise. The role of the organizational structure is most of all to coordinate and arrange the functioning of an enterprise and to enable attainment of planned goals.

It should be noted that the concept of organizational structure is still not clearly defined in the literature. There are differences in the perception of the organizational structure. It arises from many factors, but it is worth mentioning such factors as the complex nature of the organizational structure and a difficulty in the objective of extracting the entire management system. In addition, the diversity in defining the organizational structure is affected by the views and attitude of the researcher. However, some definitions of organizational structure have some points in common. It can therefore be divided into three main types of definitions, based on the elements and/or the relationship between the elements of the organizational structure. The first type of definitions are those that are focusing mainly on the elements of the organizational structure (R.W. Griffin [3]; R. Krupski [14]). The second type of definitions are those that emphasize relationships between different elements of the organizational structure (J. Zieleniewski [15]; W. Kieżun [6]; Strategor [13]; A. Schaff [11]; A. Nalepka [8]). In the third type, definition elements of the organizational structure and the relationships between them are placed on an equal footing (A. Zakrzewska-Bielawska [9]). There are also some definitions which are difficult to classify into the above three types. These definitions emphasize patterns or rules of action in the enterprise in the description of the organizational structure (H. Steinmann, G. Schreyogg [12]; M. Hopej, R. Kamiński [4]). Among the different definitions, better reflect the essence of the organizational structure that which emphasize the relationships and connections between the elements of the structure or equate elements and connections between them. The advantage of this perception of the organizational structure is that it facilitates the transition to the issue of improving the organizational structure. The problem of improving the organizational structure focuses on change of the relationship and arrangement of the elements of the organizational structure to ensure greater effectiveness.

Organizational structures have been changing along with changes occurring in enterprises. If we look at the development of industry, certain stages or directions of enterprises development can be distinguished. These directions of development were accompanied by changes within enterprises. Sometimes these changes were introduced in advance to maintain high level of enterprise operation efficiency, and sometimes the changes were forced by both internal and external factors. It can be stated however that organizational structures were evolving, just like enterprise management.

Organizational structures of enterprises have evolved from simple solutions towards more complex and sophisticated systems. Changes that have occurred in the structures of economic entities have been caused by several factors, such as strategy, type of environment, applied technology, and others. Numerous researches link the evolution of organizational structures with evolution or sometimes even revolution that has 
occurred in their environments. It can be said that changes in organizational structures of enterprises followed changes in the environment. Technological development, open borders, enhanced hyper competition, "californization of need" - all these phenomena have caused changes of enterprises, their strategies, and structures.

Evolution of organizational structures and introduction of new structural solutions is also related to development of management sciences. Classical organizational structures originate from the concept of bureaucracy and are related to organization of work applied in the 19th and 20th centuries. Classical organizational structures are hierarchical structures distinguished in respect of organizational relations. Modern organizational structures started to emerge in 1990 s, when such management concepts were developed as lean management, outsourcing, reengineering, knowledge management, process management, and others. Now, such concepts like insourcing, cloud computing, and agile enterprise affect the global business [2]. All these concepts significantly modify enterprises' way of operation and, consequently, require adjustment of organizational structures. The opportunity to introduce structural changes is also created, or even enforced by the development of information technology. However, despite emergence of many modern structural solutions, classical organizational structures are still commonly applied in enterprises. They are a kind of "basis" on which additional structural solutions are introduced which are conducive to effective operation.

The themes of changes of organizational structures are particularly interesting in the research concerning the Polish enterprises. They did not have as much time for evolution as American or European companies. Changes in the structures of Polish enterprises were introduced suddenly, as a kind of response to the changes in their general conditions of functioning. Polish enterprises, both large and small, started to implement solutions applied commonly abroad. It seems therefore interesting to analyze how organizational structures of Polish enterprises are currently being shaped, and also whether they have changed during the last years of crisis and to what extent. The aim of the article is to answer these questions. Directions of changes in the organizational structures of SME operating in Poland were established on the basis of a quantity research. The author assumed not only that the organizational structures of SME are flexible, but also recently increased their flexibility. In the following parts of the article, will be presented methodology of the research, form of the organizational structure of SME, and changes in the organizational structures of SME. At the end the main conclusions of the research and directions for further research will be outlined.

\section{Methodology of the research on the changes of organizational structures of SME}

Analysis of changes in the organizational structures of enterprises from the SME sector was one of the elements of a scientific project aimed at identification of organizational structures of this group of enterprises, carried out in 2012-2013 under the direction of W. Jakubowska [5].

Changes in the organizational structures of SME were analyzed using a sample of 380 companies from the SME sector. The research was carried out using the Computer Assisted Telephonic Interview (CATI) method, which made it possible to analyze a large group of enterprises. The CATI research was ordered to the "Indicator. Centrum Badań Marketingowych" company. The research sample was drawn out from the Hoppenstedt \& Bonnier base as of the end of 2010, comprising information on business entities operating across Poland. The sample was an equinumerous stratified sample. The research was carried out in three strata, distinguished on the basis of the number of employees working in an enterprise, which corresponded with three groups of enterprises: micro-, small, and medium-sized ones. Percentage shares of particular enterprise groups in the entire research sample are presented in Fig. 1.

Other parameters describing the research sample are: age of an enterprise, industry sector, legal and organizational form, and origin of capital. Enterprises under research differed in respect of their year of establishment. A majority of them, i.e. $66.3 \%$, were established during the transformation period, which is between 1989 and 2004. About 19.5\% accounted for enterprises created before the transformation period, while $14.2 \%$ were those established after Poland's joining the European Union. Taking the industry sector into account, production enterprises accounted for $39.7 \%$, service providing enterprises were $33.4 \%$, trade enterprises were $20.5 \%$, and enterprises of the administration sector were $6.3 \%$. 


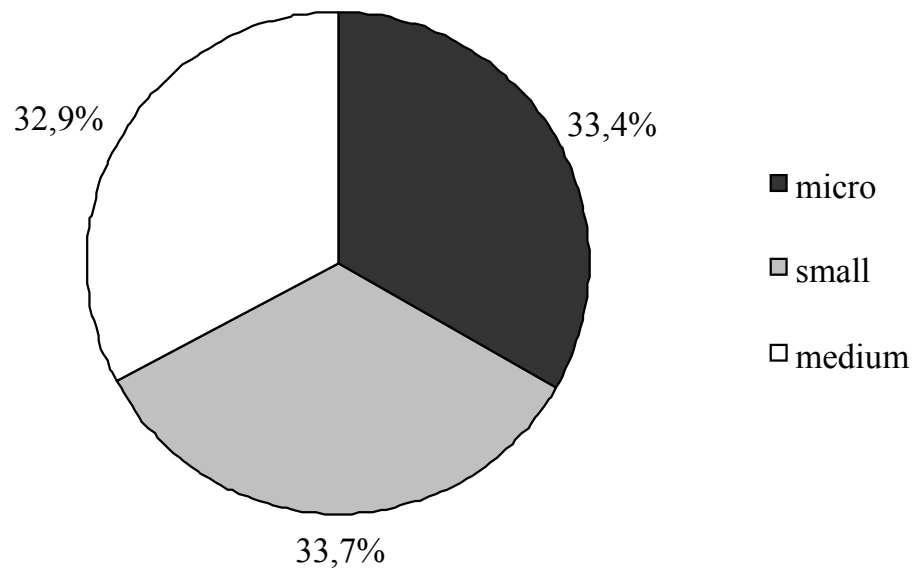

Figure 1. Description of the research sample in respect of number of enterprise employees

In respect of the organizational and legal form, limited liability companies were prevailing (63.9\%). Due to the origin of the capital dominated companies with national capital (72.4\%).

Analysis of changes in the organizational structure of SME was preceded by statistic evaluation of various aspects of organizational structure. Parameters such as centralization, formalization, standardization, and configuration were considered. Each parameter was evaluated according to a five-point scale, where 1 meant a very low level and 5 meant a very high level. For the configuration parameter, a question about the exact number of levels was asked.

Analysis of the parameters characterizing the organizational structure is a multidimensional approach which allows for a better description of the organizational structure than mapping it to one of the types shown in the literature. This approach allows identifying the characteristics that can be associated with the flexibility and positive impact on the results achieved by the enterprise.

Because of a multidimensional approach to the analysis of organizational structure, analysis of directions of changes was also carried out from the perspective of changes in various dimensions of organizational structure. They were examined using questions about the direction of changes that have occurred during the last few years in an enterprise.

The research therefore consisted in subjective evaluation of changes in the organizational structure of respondents, who were mainly the owners and managers of enterprises. They were asked about basic dimensions of the organizational structure, which are: centralization, formalization, standardization, as well as changes in configuration, i.e. the number of levels and organizational units. Changes in each dimension of the organizational structure were evaluated according to threepoint scale, were 1 meant lowering the level of the analyzed parameter of the organizational structure, 2 meant no changes in the level of the analyzed parameter of the organizational structure and 3 meant raising the level of the analyzed parameter of the organizational structure. Directions of changes were identified both for the entire research sample and from the perspective of a particular category of enterprises.

\section{Form of the organizational structure of SME}

Discussing directions of changes in the organizational structure of SME requires outlining the shape of organizational structure that emerged on the basis of the research. However, since it is not the main subject of this article, it will only be discussed in short. Only facts that are significant for further deduction will be presented.

Organizational structure of an enterprise can be described according to various dimensions. The most common approach is that of the Aston University researchers [10] who distinguished five basic parameters of the organizational structure, which are: specialization, standardization, formalization, centralization, and configuration. This article identifies the following parameters of the organizational structure: centralization, formalization, standardization, and configuration.

The way these organizational structure parameters of the analyzed enterprises were formed is discussed as follows. 
First, the centralization dimension was analyzed as a part of the research on SME organizational structures. Centralization consists in taking away decision rights and allocating them to higher level managers. It turned out that among the 380 analyzed enterprises, as much as $71.8 \%$ declared high and very high level of centralization, $23.7 \%$ of the enterprises under research reported medium level of decision centralization, and very few $(4.5 \%)$ reported low or very low level of centralization.

The level of formalization of enterprises under research was also relatively high. Formalization sets company patterns of behavior and is reflected by the number of documents, their level of detail, and strictness of their use. High and very high level of formalization was declared by $41.1 \%$ of enterprises, while $40.8 \%$ of them declared medium level of formalization. It can be therefore stated that over $80 \%$ of enterprises declare medium or higher level of formalization.

The level of standardization in the analyzed enterprises was also high. Standardization consists of unification of the enterprise's way of functioning. It therefore means limiting discretion of action, but also ensures unified ways and rules of behavior. About $61.1 \%$ of enterprises declared that their level of standardization of actions was high or very high, while $33.4 \%$ of enterprises described their level of standardization as medium. Again, if we aggregate results, it turns out that over $90 \%$ of enterprises describe their standardization level as medium or more than medium.

The last analyzed dimension of organizational structure is configuration. The configuration dimension concerns the structure of an enterprise in respect of its system and relations among particular units, departments, etc. Configuration is closely related to the hierarchy, and thus this dimension is often directly called "the hierarchy". The research proved that enterprises from the SME sector are characterized by a medium level of complexity. Average number of levels in the analyzed sample was 3.42 , and the median was 3 . As much as $46 \%$ of enterprises declared having three organizational levels, and $37 \%$ of enterprises reported having more than 3 organizational levels. In respect of the number of levels they can be therefore classified more as leptokurtic than platykurtic.

Summing up, we can state that small and medium-sized enterprises have rather mechanistic organizational structure. It was proved that organizational structures of the analyzed enterprises had a high level of formalization and standardization of actions, centralization of decisions, and relatively high number of organizational levels.

\section{Changes in the organizational structures of SME}

The author wanted to learn whether the above description of organizational structures is the effect of changes that have occurred in the organizational structures of the analyzed enterprises in the recent years. The aim of the research was therefore to answer the question about the way some organizational structure dimensions in the analyzed enterprises have changed in the last years. Directions of changes in the selected organizational structure dimensions are presented below for the entire group of SME, broken into categories according to the number of their employees.

Changes in the level of centralization of SME were analyzed first. The analyzed enterprises had a high level of centralization and it turns out that this dimension has not changed during the last few years $(58 \%$ of enterprises reported so). What is more, as much as $24 \%$ of enterprises declared that their level of centralization had grown during the last years (Fig. 2).

Interestingly, definitely the largest number of small enterprises declared lack of changes in respect of centralization level (63.3\%). About $17.2-18.4 \%$ of entities in each group of enterprises declared lowered level of centralization. The largest number of entities in the group of medium-sized enterprises declared increasing the level of centralization (28\%). Detailed structure of answers concerning the changes in the centralization level broken into categories is presented in Fig. 3.

Another dimension analyzed in respect of changes that have occurred was the level of formalization. The research showed that the level of formalization of small and medium-sized enterprises is high, so the respondents were asked about the directions of changes in the level of enterprise formalization. Most respondents consider that the level of formalization has not changed during the last few years. However, among those who consider that the level of enterprise formalization has changed, as much as $25 \%$ of respondents report that it has grown (Fig. 4). 


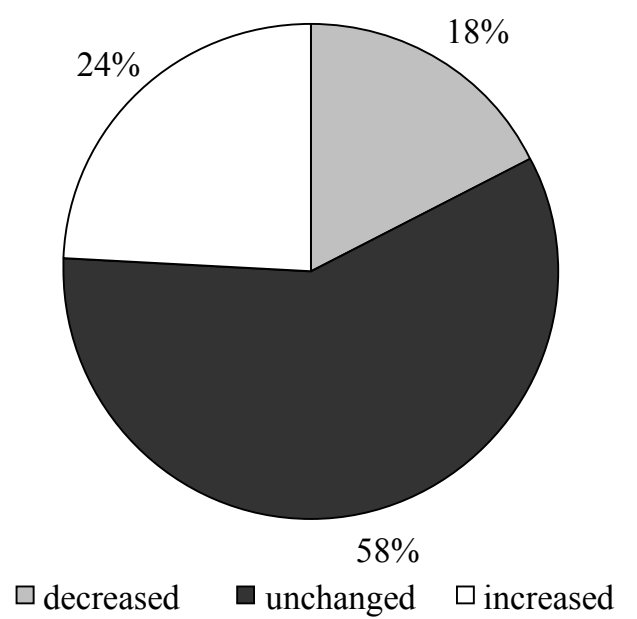

Figure 2. Changes in the level of centralization of SME

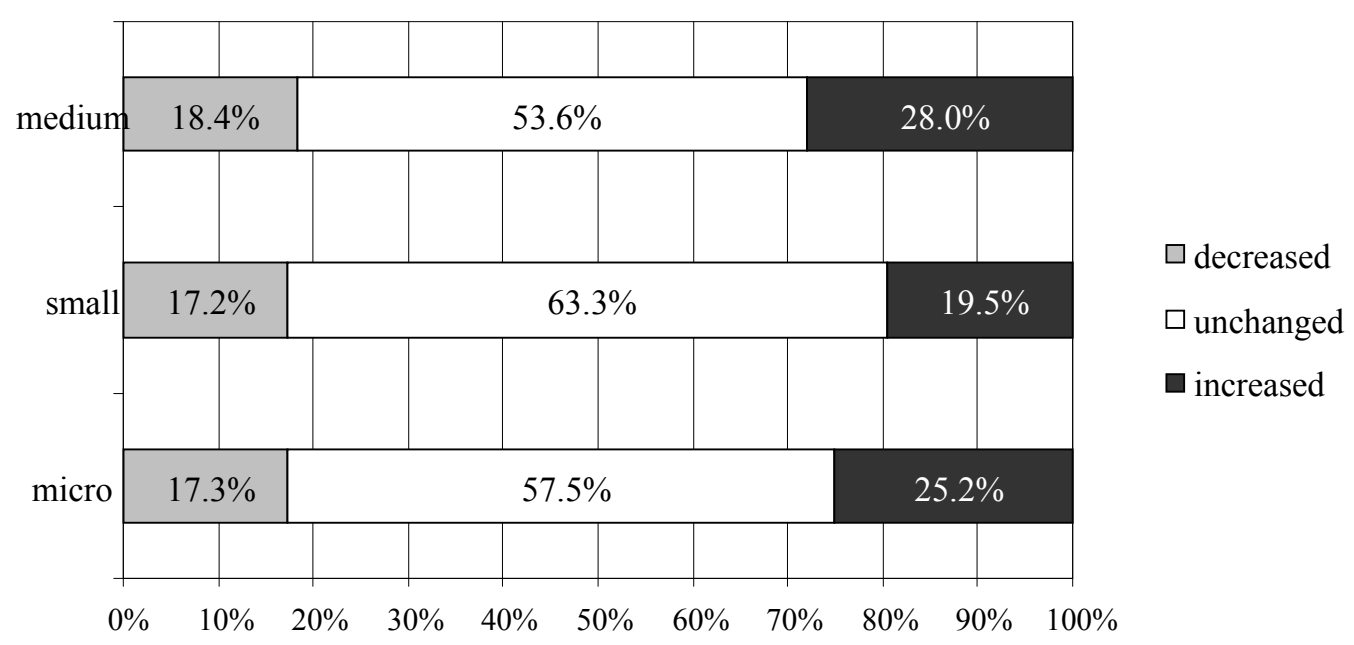

Figure 3. Changes in the level of centralization according to categories of SME

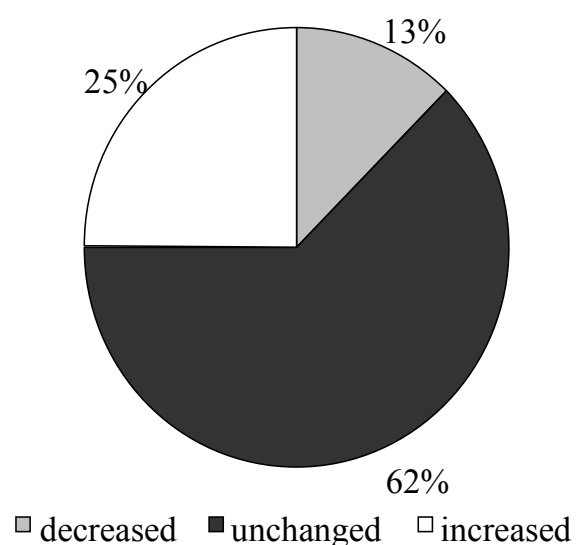

Figure 4. Changes in the level of formalization of SME 


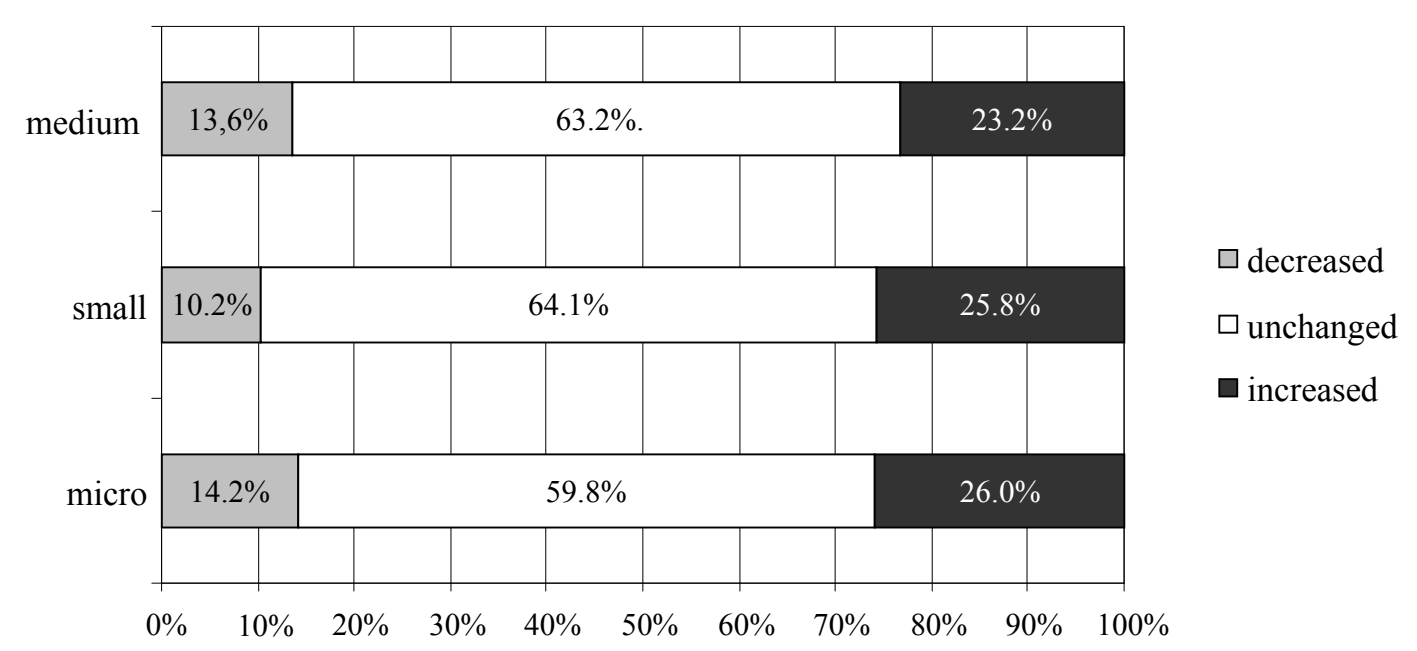

Figure 5. Changes in the level of formalization according to categories of SME

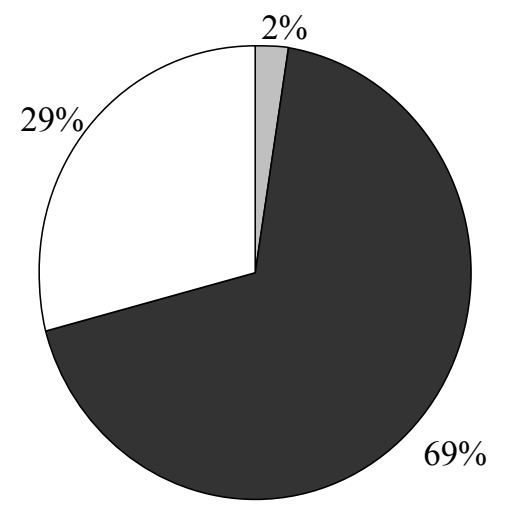

$\square$ decreased $\square$ unchanged $\square$ increased

Figure 6. Changes in the level of standardization of SME

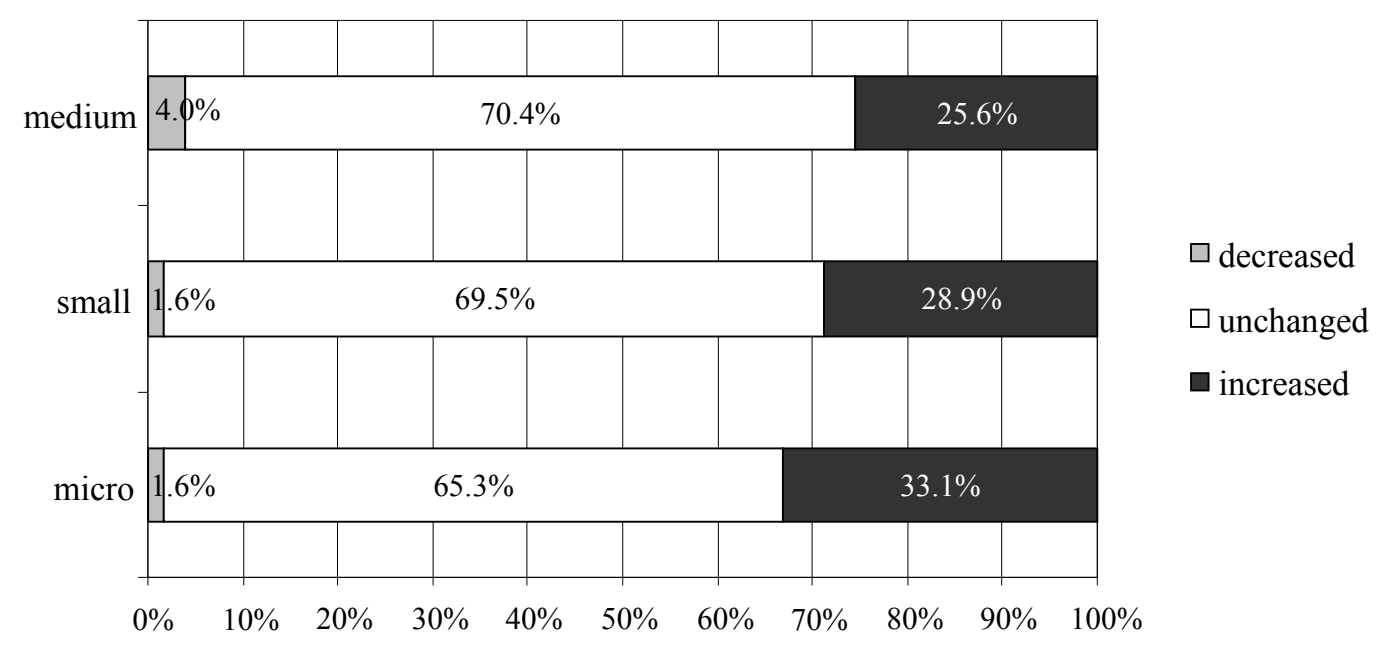

Figure 7. Changes in the level of standardization according to categories of SME 
Similar results concerning the perception of changes in the level of enterprise formalization were observed in each of the research groups. Most of them declared lack of changes in the formalization level, and if any changes were recorded, these were directed towards raising the formalization level of an enterprise. Detailed structure of answers concerning the changes in the formalization level broken into categories is presented in Fig. 5.

Another analyzed parameter was the standardization of actions. Most respondents (69\%) consider that the level of standardization has not changed during the last few years. Among enterprises that have recorded changes in the standardization level as much as $29 \%$ indicated changes towards enhanced standardization (Fig. 6).

The analysis of changes in the standardization level broken into the groups of enterprises also showed that it has not been changed. About $65-70 \%$ of enterprises answered so. However, if any changes have occurred, these have been changes towards enhancement of standardization of actions. Interestingly, it was true mainly for micro-sized enterprises. It was observed that the bigger the size of enterprises, the smaller number of them declared raising the level of standardization during the last few years. Detailed structure of answers concerning the changes in the standardization level broken into categories is presented in Fig. 7.

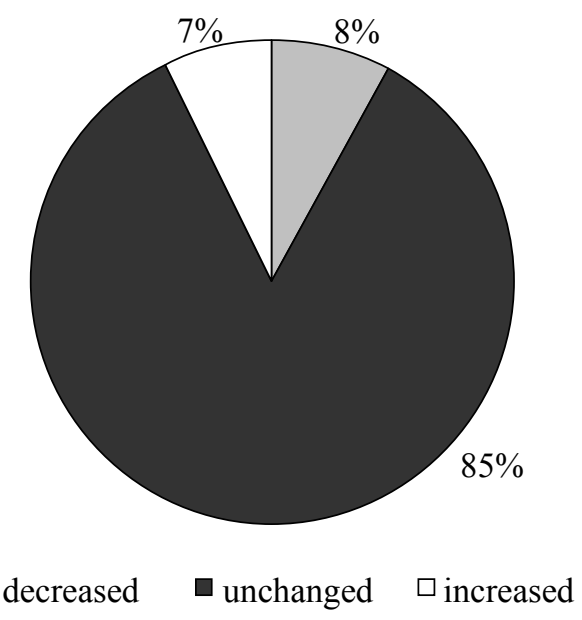

Figure 8. Changes in the number of organizational levels of SME

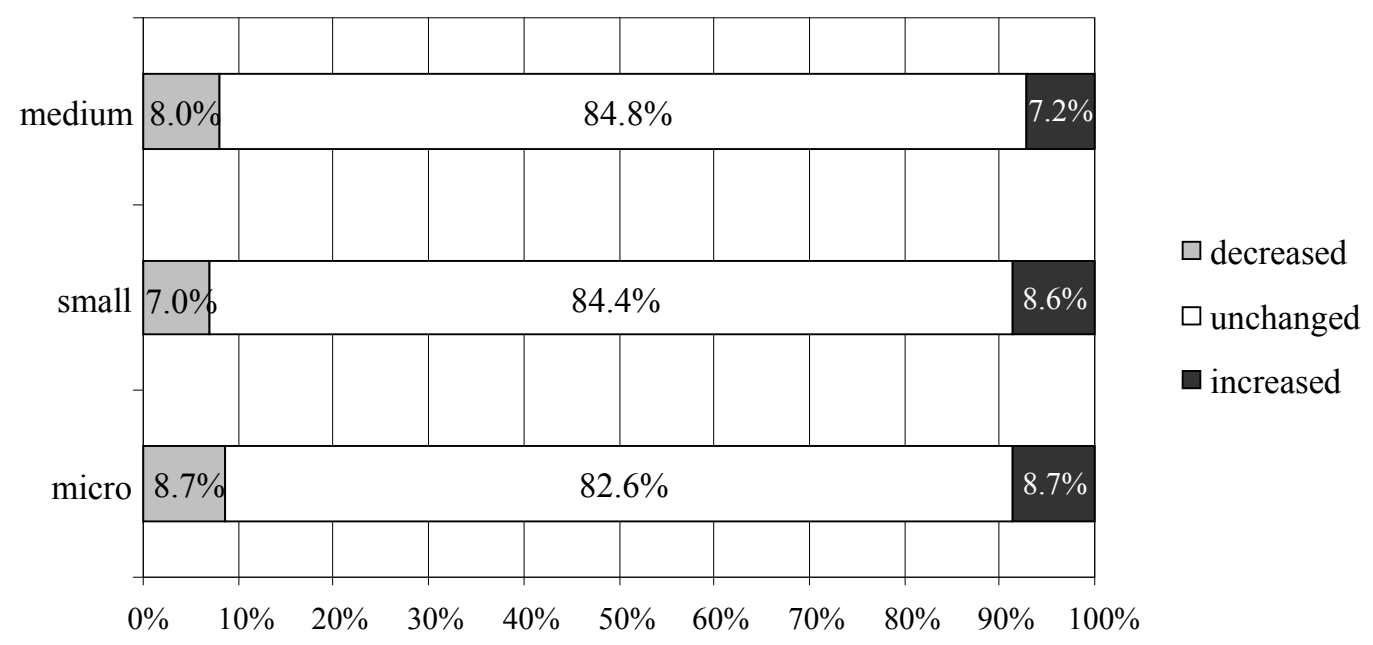

Figure 9. Changes in the number of organizational levels broken into categories of SME 
The configuration dimension was also analyzed in addition to the level of centralization, formalization, and standardization. As a part of the research concerning the changes in the organizational structure a question about the change in the number of organizational levels and units in enterprises was asked. Analysis of changes in the number of organizational levels showed that it was not changed in $85 \%$ of enterprises. However, among enterprises introducing changes a similar number of those which increased the number of organizational levels was reported to those which decreased the number of organizational levels (Fig. 8).

The division of SME into categories led to conclusions similar to those stemming from the analysis of the entire group. The enterprises were not eager to add another organisational level to their structures. Detailed structure of answers concerning the changes in the number of organizational levels broken into SME categories is presented in Fig. 9.

An analysis of changes in the number of organizational units showed that enterprises more willingly introduced changes in this scope. Over $40 \%$ of respondents declared changing the number of organizational units. Similar groups have increased and decreased the number of organizational units (Fig. 10).

After dividing the enterprises into groups on the basis of the number of their employees, it turned out that the biggest numbers of changes were introduced by medium-sized and small enterprises. It was also observed that in the group of small enterprises, definitely more of them indicated growth of number of organizational units. Detailed structure of answers concerning the changes in the number of organizational units broken into SME categories is presented in Fig. 11.

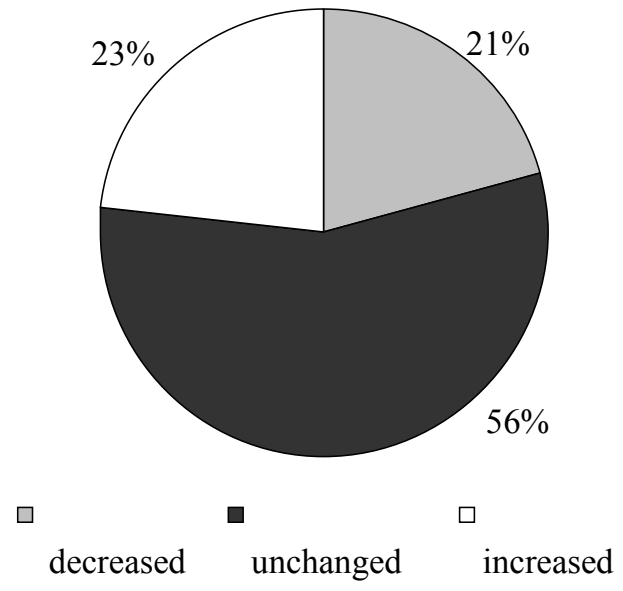

Figure 10. Changes in the number of organizational units of SME

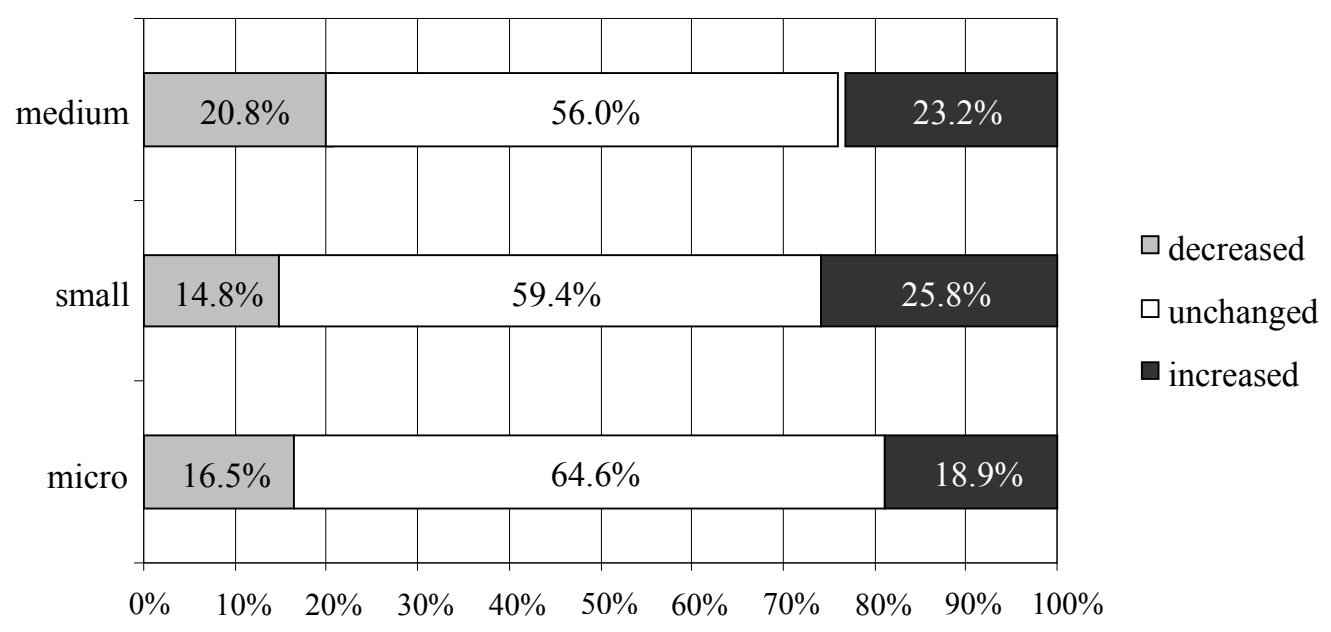

Figure 11. Changes in the number of organizational units broken into categories of SME 
Table 1. Directions of changes in parameters of organizational structure of SME enterprises in percentage terms

\begin{tabular}{|c|c|c|c|}
\hline Structure parameters & Description of parameter & \multicolumn{2}{|c|}{$\begin{array}{l}\text { Directions of changes } \\
\text { in recent years }\end{array}$} \\
\hline \multirow{3}{*}{ Centralization } & \multirow{3}{*}{ High level } & $\uparrow$ (growth) & $24 \%$ \\
\hline & & - (no changes) & $58 \%$ \\
\hline & & $\downarrow \quad($ drop $)$ & $18 \%$ \\
\hline \multirow{3}{*}{ Formalization } & \multirow{3}{*}{ High level } & $\uparrow$ (growth) & $25 \%$ \\
\hline & & - (no changes) & $62 \%$ \\
\hline & & $\downarrow$ (drop) & $13 \%$ \\
\hline \multirow{3}{*}{ Standardization } & \multirow{3}{*}{ High level } & $\uparrow$ (growth) & $29 \%$ \\
\hline & & - (no changes) & $69 \%$ \\
\hline & & $\downarrow \quad($ drop $)$ & $2 \%$ \\
\hline \multirow{3}{*}{ Configuration } & \multirow{3}{*}{$\begin{array}{l}\text { Medium and large number } \\
\text { of organizational levels }\end{array}$} & $\uparrow$ (growth) & $7 \%$ \\
\hline & & - (no changes) & $85 \%$ \\
\hline & & $\downarrow \quad($ drop $)$ & $8 \%$ \\
\hline
\end{tabular}

\section{5}

\section{Recapitulation}

The author was curious whether and what changes were introduced by enterprises in their organizational structures. The research showed a lack of significant changes in the organizational structures of micro-, small, and medium-sized enterprises during recent years. Additionally, no significant differences in particular subgroups of enterprises were observed in comparison to the entire group under research. Detailed specification of the analyzed parameters of the organizational structure with their general description and recorded changes in their level is presented in Table 1.

Most enterprises have not introduced significant changes in respect of centralization, standardization, or formalization, as well as in respect of the number of organizational units and levels. The enterprises had a high level of formalization and standardization of actions, as well as centralization of decisions. They also covered structures with a relatively developed number of organizational levels.

These dimensions also have not changed during recent years. A prevailing number of enterprises have not indicated any changes in these parameters. Among the enterprises which reported changes in the organiza- tional structure parameters, a vast majority indicated growth of the parameters, except the parameter of configuration understood as a number of organizational levels.

The structure of the investigated enterprises was classified as mechanistic. In addition, the changes which take place in the organizational structures have stiffening of the organization. The enterprises became even less flexible. The lack of changes of organizational structures is particularly interesting in the context of crisis, because the crisis is a symptom of a turbulent environment. With instability of environment is connected concept of the flexible organizational structures. It is understood that in such conditions, the companies should have a flexible organizational structure or make changes to it in the direction of their flexibilizing.

This conclusion was confirmed by numerous studies carried out, inter alia, by T. Burns and G.M. Stalker [1] and P. Lawrence and J. Lorscha [7].

They showed that companies operating in unpredictable surroundings and having less formalized structure were gaining better economic performance. However, completely different results were obtained in the study of SME. 
It turned out that despite worse a economic situation less than half of the enterprises had implemented changes in their organizations.

Simultaneously, changes consisting in reducing organizational units or the number of levels were reported in less than one-fifth of the analyzed enterprises. It is possible that the analyzed enterprises managed to do well in the crisis period or maybe they introduced changes in the organizational structure right after the beginning of the crisis, adapting the structure to the external conditions.

The author supports conclusions stemming from other researches, according to which enterprises apply proven, classic structural solutions and only when a specific need arises, they implement smaller modern solutions. It is also possible that the few-years period about which the enterprises were asked is not enough to introduce changes in organizational structures. Their evolution takes more time or is not clearly recorded by the respondents. It can be presumed that the evolution of organizational structures of small and medium-sized enterprises is very slow.

Described studies should be deepened in qualitative research because of the complexity of organizational structures. In addition, it would be worthwhile to repeat this study using the method of in-depth interviews with members of management, as well as on another sample of enterprises. Comparison of the results would be very interesting.

\section{$6 \quad$ References}

[1] Burns T., Stalker G.M. - The management of innovation. Tavistock, London 1961.

[2] Chudzicka J. - Insourcing as a New Trend in Global Business [in] Foundations of Management, Vol. 05, Nr 02 (10), 2013.

[3] Griffin R.W. - Podstawy zarzqdzania organizacjami. PWN, Warszawa 2010.

[4] Hopej M., Kamiński R. - Struktury organizacyjne współczesnych organizacji. OW Politechniki Wrocławskiej, Wrocław 2010.

[5] Jakubowska W. - Ewolucja struktur organizacyjnych $w$ teorii $i$ praktyce. Raport $\mathrm{z}$ badań statutowych SGH, Warsaw 2013.

[6] Kieżun W. - Sprawne zarzqdzanie organizacja. OW SGH, Warszawa 1997.

[7] Lawrence P., Lorsch, J. - Differentiation and Integration in Complex Organizations [in] Administrative Science Quarterly, Vol. 12, Iss. 1, 1967.

[8] Nalepka A. - Struktura organizacyjna. Antykwa, Kraków 2001.

[9] Podstawy zarzqdzania. Teoria $i$ ćwiczenia (ed. A. Zakrzewska-Bielawska). Oficyna Wolters Kluwer business, Warszawa 2012.

[10] Pugh D.S., Hickson D.J, Hinings C.R., Turner C. Dimensions of Organization Structure. Administrative Science Quarterly, 1968.

[11] Schaff A. - Szkice o strukturalizmie. Wyd. Książka i Wiedza, Warszawa 1983.

[12] Steinmann H., Schreyögg G. - Zarzadzanie. Podstawy kierowania przedsiębiorstwem. Wyd. Politechniki Wrocławskiej, Wrocław 1998.

[13] Strategor. Zarzadzanie firma. Strategie, struktury, decyzje, tożsamość. PWE, Warszawa 1996.

[14] Zarzqdzanie przedsiębiorstwem $w$ turbulentnym otoczeniu (ed. R. Krupski). PWE, Warszawa 2005.

[15] Zieleniewski J. - Organizacja i zarzqdzanie. PWN, Warszawa 1981. 